\title{
Reflexiones en torno a la asombrosa complejidad de lo humano
}

Norma Alicia del Rio Lugo ${ }^{1}$

Universidad Autónoma Metropolitana, México

\section{Rescate de libro}

Magagna, J. y Juárez, C. (Comp.) (2012). Observación de bebés: El método Ester Bick de la Clínica Tavistock. México: Paidós. 374 pp.

Material original autorizado para su primera publicación en el Journal de Ciencias Sociales, Revista Académica de la Facultad de Ciencias Sociales de la Universidad de Palermo

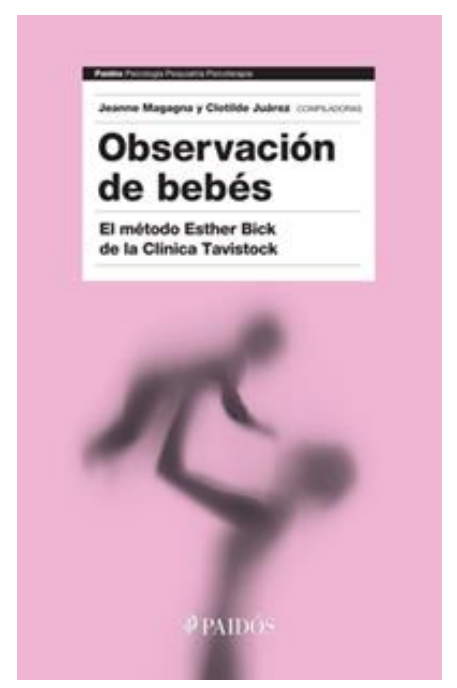

Resumen: Este es un libro que trata sobre el ser como sede de relaciones y no sólo porque el tema central sea el desarrollo afectivo de los bebés, sino por todo el entramado de relaciones creadas con los adultos cercanos, como por las y los profesionales que monitorean la relación de apego temprano y que comparten una formación especializada de la Clínica Tavistock. En este Centro inglés se ha desarrollado una metodología de observación formal pero no exenta de implicaciones transferenciales, material con el que se trabaja en la supervisión.

Esta metodología constituye una crítica a la atención aséptica hospitalaria, renunciando también a las relaciones de poder establecidas en el formato de atención a la salud. El observador está a disposición de los recursos familiares y acata las posibles decisiones de

\footnotetext{
${ }^{1}$ Magister en Lingüística (Colegio de México). Magister en Rehabilitación Neurológica por la UAM-Xochimilco. Profesora Investigadora de Tiempo Completo Titular División de Ciencias Sociales y Humanidades en el Departamento de Educación y Comunicación, área de Investigación en Epistemología y seminarios de investigación para el trabajo finales de graducación.
} 
dar por terminado el acuerdo de observación y se renuncia a la asimetría hegemónica de los procedimientos de intervención usuales, en la que es el profesional el que sabe, el que actúa, el que aconseja, el que guía, para adoptar el reto de enfrentar con ellos la incertidumbre del no saber, de suspender los juicios y reacciones emergentes.

El lector o lectora encontrará un amplio espacio de reflexión sobre su capacidad empática, su capacidad de hacer silencio para que entre el otro y poder vislumbrar la potencia que encierra el desarrollo de una nueva vida.

\section{Introducción}

En toda intervención integral diseñada para transformar y mejorar la calidad de vida de personas que viven en situaciones que los desbordan y que se expresan de manera diversa como enfermedades, violencia, maltrato, sufrimiento, se enfatiza el valor de la creación o fortalecimiento de las redes de apoyo con que se cuenta. Observación de bebés. El método Ester Bick de la Clínica Tavistock, es un libro colectivo de once autores ingleses y latinoamericanos, compilado por Jeanne Magagna y Clotilde Juárez, que describe el profundo compromiso desinteresado que puede darse y construirse a lo largo de intervenciones sistémicas, con una duración intensa y de largo alcance (observaciones semanales de uno a tres años con una familia, además de sesiones de supervisión detallada y minuciosa desde todos los ángulos).

\section{Comentarios}

El encuadre de la intervención posee las características éticas del consentimiento informado y hay un reconocimiento del elemento intrusivo que supone todo dispositivo de intervención aun cuando sea el más silencioso y prudente posible. El observador está a disposición de los recursos familiares y acata las posibles decisiones de dar por terminado el acuerdo de observación y se renuncia a la asimetría hegemónica de los procedimientos de intervención usuales, en la que es el profesional el que sabe, el que actúa, el que aconseja, el que guía, para adoptar el reto de enfrentar con ellos la incertidumbre del no saber, de suspender los juicios y reacciones emergentes, para no acallar la voz y la subjetividad del "otro", del bebé-la madre-el padre en la "realidad" de su propio proceso de desarrollo que tiene un tiempo propio, que no puede ser apresurado por la ansiedad de quien puede pensar "que lo sabe todo".

Puede uno estar o no de acuerdo con el marco particular interpretativo en este caso el Psicoanalítico Kleiniano, que postula intensas ansiedades primarias y secundarias que 
movilizan la organización afectiva en la vida de un bebé que no cuenta con las competencias funcionales superiores de la razón lógica, la simbolización y el lenguaje. El tratamiento del significado libidinal que pretende describir esa intensidad vivencial de quien todavía carece de marcos socioculturales, puede parecer fantasioso e irreal para el lector, que puede preferir que se le hable en términos menos explícitos y más fríos. Sin embargo, aún si negamos este abordaje interpretativo, queda todavía un hilo de continuidad que sigue hablando en lo profundo, de ansiedades pre-verbales que todos hemos experimentado cuando vivimos algo tan intenso, como puede ser la conciencia de que somos mortales. Esa vulnerabilidad que da razón de nuestra dignidad humana y que nos pone en el rasero común de conciencia: esa experiencia "cruda" que hemos pretendido cocinar a lo largo de nuestra existencia como especie humana.

Es la nuda vita como dice Agamben, la zoé de los griegos, como vida pura, fuerza biológica que marca nuestro punto de partida hacia la búsqueda del bios que marca la vida relacional, base fundacional del lenguaje, la política, la ciudadanía. Es en esta contradicción dinámica que se despliega la persona humana, tema central de este libro.

Aunque es un libro que pone sus reflectores en el ámbito de lo más privado, es decir lo que consideramos experiencias íntimas familiares, generalmente reacias a desplegarse ante los ojos de extraños, a medida que avanzamos en su lectura, nos deja ver los entramados históricos de cómo se genera esta corriente de atención a la calidad de los afectos: es la época de posguerra en Europa, específicamente Inglaterra, de atención institucional a huérfanos y a desplazados. Se requiere restaurar heridas profundas por las diversas pérdidas y voltear la mirada hacia un nuevo comienzo, evaluar las potencialidades de crecimiento vital. Pero se tiene la conciencia de que este trabajo de reconstrucción requiere tiempo y voluntad de reemprender hacia nuevos horizontes.

Medio siglo después, nos vemos aquí con muchas situaciones comunes todavía en una guerra sórdida y subterránea persistente. Con la necesidad de "adherirse" -palabra usada una y otra vez en el libro- a la esperanza. Me pregunté: ¿Qué ha pasado en este medio siglo con este abordaje? La sección de aplicaciones teóricas del libro me dio la respuesta, al encontrarme ahora en el ámbito de los tribunales para la protección integral de niños maltratados y de luchar por mostrar la voz de los infantes "aquellos sin habla" mediante evidencia que muestre la sensibilidad del niño y su potencial afectivo, gracias a un particular "oído musical" y observación detallada. La práctica hospitalaria mostró también la cara dura de la moneda y la necesidad de recordar que hay sufrimiento, pérdidas, soledades, además de tratar como algo local, los problemas crecientes de reflujo gastroesofágico en bebés como lo hace tercamente Esperanza Pérez de Pla con su equipo de investigación en el Hospital Infantil de México, cuando nos acercamos a la tan deseada formación afectiva y humanista 
de los pediatras y demás equipo "psi", al hacer posible "un tiempo especial" de observación cercana de sus pacientes, con otros lentes que los acerquen en lugar de distanciarlos y darles ese espacio posible de contención y reflexión grupal que evite el famoso burn-out profesional.

Muy probablemente las lágrimas nos acompañen en la lectura, conforme nos movamos también en la unidad de cuidados intensivos neonatales y observemos todo el proceso para desmontar el aislamiento, las corazas técnicas, los procedimientos especializados que prolongan y legitiman el sufrimiento de Ana, separada totalmente de sus padres, hasta que paradójicamente la muerte los convoque a aceptar lo que desde un principio se veía venir.

Descubrí la Revista especializada en Observación de bebés, mencionada en uno de los capítulos y encontré temas propios del modernismo como relacionar el desarrollo cerebral con el desarrollo afectivo, pero también con temas muy posmodernos: la familia inglesa abierta a la diversidad con familias afrodescendientes, o de Bangladesh que -aunque no pude leerlo, imagino- deben añadir nuevas vetas que nos reflejen que nuestra concepción de "bebé" y de "crianza", quizá no sean tan universales como lo damos por hecho y que quizá otros modos de cuidado, susciten otros conflictos, que quizá la exclusividad de la madre y del padre como fuente de apoyo materno no sea el único escenario posible. Pensemos ahora en los padres cuidadores, las abuelas, o los "profesionales" que atienden en las estancias infantiles. $Y$ justo encontré un artículo escrito por Mónica Cardenal, autora de uno de los capítulos de este libro sobre las vicisitudes de una pequeña que pasa más de 10 horas al cuidado de "otros": cómo esta bebé de sólo 9 meses cambia su horario de sueño para estar con la madre por la noche y las demandas de "comportarse a la altura de las expectativas de las cuidadoras" que deben asegurar que haya comido bien como señal de calidad de cuidado. El último capítulo del libro cierra con una apretada síntesis de los desarrollos actuales de posibles modelos de intervención y apoyo a profesionales jurídicos y de la salud y ofrece a manera de enlace, múltiples referencias bibliográficas que puede uno buscar para seguir la trama infinita de posibilidades de reflexión sobre quiénes somos.

A pesar de estas complejidades, las autoras mantienen principios bastante sabios desde mi punto de vista para la supervisión de quienes se encuentran en la tarea de crecer emocionalmente para apoyar a otros: evitar el uso de lenguaje técnico con ideas preconcebidas que racionaliza, aleja, e impide que se mantenga el contacto con el impacto emocional de la narración de lo que pasa entre seres humanos a los que les importa el otro.

Se promueve la articulación de vinculaciones en donde se juegan las diversas identidades que todas están en continuo cambio y crisis. Nadie queda exento de ello y todos trabajan sus afectos y reflexionan sobre sus capacidades de contención tanto personal como 
interpersonal. Son redes de apoyo intensas y cercanas que van más allá de la disponibilidad y presencia, en un acompañamiento solidario y de co-construcción.

Impresiona también como todos somos reflectores de los afectos y ansiedades de los demás: este sentido de empatía que nos hace profundamente humanos y el valor de la observación como este dispositivo terapéutico para poder diferenciar entre el yo-tú y evitar entrar en un juego de reflejos, para mediante la reflexión grupal en la verbalización de lo innombrable, pueda organizarse estos recursos afectivos, elaborarlos con la propia memoria histórica común de la infancia y resignificarlos para promover el desarrollo humano.

\section{Conclusión}

Suspender nuestro discurso para dar lugar y espacio a otro comienzo, para evitar constreñir la libertad para "ser". El poder queda del lado del habla y hay que hacer silencio para que pueda habitarse el espacio de lo que Eduardo Bustelo llama la pura posibilidad, de recrear otra gramática de sentido que no sea la opresora del deber.

Estas relaciones no están pues fundadas en la Ética del deber y la justicia, sino en la ética de lo que ahora se ha denominado como la Ética del cuidado y la responsabilidad infinita por el reconocimiento de la alteridad en una relación horizontal recíproca. Así como el epígrafe inicial vuelvo a cerrar con las reflexiones de William Ospina:

¿Quién nos enseñará la prudencia, la paciencia, la lentitud, el arte de volver a empezar? ¿Quién nos hará saber que en nuestras respuestas instintivas, tal vez estén convulsiones y miedos que no son estrictamente humanos, el giro del pez en el fondo del mar, la reacción del reptil ante lo que avanza, el temor y la tentación ante el abismo del pichón en la punta de la rama? 